\title{
e-Migrinter
}

$8 \mid 2012$

Regards sur les migrations sud-asiatiques

\section{Claire Zalc, Melting Shops. Une histoire des commerçants étrangers en France}

\section{Marie Chabrol}

\section{(2) OpenEdition}

\section{Journals}

Édition électronique

URL : https://journals.openedition.org/e-migrinter/667

DOI : 10.4000/e-migrinter.667

ISSN : 1961-9685

Éditeur

UMR 7301 - Migrinter

\section{Édition imprimée}

Date de publication : 4 avril 2012

Pagination : 137-138

ISSN : 1961-9685

\section{Référence électronique}

Marie Chabrol, «Claire Zalc, Melting Shops. Une histoire des commerçants étrangers en France », eMigrinter [En ligne], 8 | 2012, mis en ligne le, consulté le 20 mai 2021. URL : http://

journals.openedition.org/e-migrinter/667 ; DOI : https://doi.org/10.4000/e-migrinter.667 


\section{Zalc, Claire (2010) Melting Shops. Une histoire des commerçants étrangers en France, Paris, Perrin, 330 p.}

\section{Marie Chabrol}

$\mathbf{L}$ ouvrage de Claire Zalc, tiré de sa thèse soutenue en 2002, est riche de connaissances sur deux mondes, autant sujets aux idées reçues qu'ils sont l'un et l'autre méconnus : celui de la boutique et celui des petits entrepreneurs étrangers en France, tout au long du XIX $^{\mathrm{e}}$ siècle et jusqu'aux années 1930. Alors que l'accession au statut d'entrepreneur ou de commerçant est communément pensée comme l'aboutissement d'un parcours professionnel ascensionnel pour un étranger, forcément spécialisé dans un métier associé à son origine nationale («tailleur juif», "maçon italien », etc.), Claire Zalc surprend le lecteur dès les premières lignes de l'introduction en racontant les quelques mois que Norbert Elias a passés à Paris en 1933, durant lesquels il a difficilement survécu en fabricant et en vendant des jouets en bois. Le monde universitaire français était fermé au sociologue allemand, mais celui de la boutique lui était ouvert, comme à tout étranger, réfugié politique ou migrant économique, et quel que soit son statut dans son pays d'origine.

Pour le non-spécialiste, c'est là la première découverte de l'ouvrage de Claire Zalc: la liberté de commerce, héritée de la Révolution française, qui ouvre le monde de l'entreprise à tous, sans condition de nationalité. Ce principe a permis à des entrepreneurs européens ou même américains de s'installer et de prospérer en France tout au long du XIX ${ }^{\mathrm{e}}$ siècle. Il a aussi favorisé l'insertion économique de migrants, venus parfois du monde de l'industrie, ou de réfugiés fuyant l'Allemagne et l'Autriche dans les années 1930. Si les contours de ce groupe social très hétérogène sont devenus de plus en plus flous, au fil du temps et de la diversification des origines nationales, deux points unissent cependant tous ces entrepreneurs: leur indépendance, par rapport à un patron et à l'Etat, et la non appartenance à la nation française. L'auteure montre comment, durant la Première Guerre mondiale, le problème posé par le second point devient un moyen de revenir peu à peu sur les principes d'indépendance: «le contrôle des étrangers apparaît comme le principal alibi idéologique des pratiques d'identification dans le monde du commerce, monde plutôt hostile au regard de l'Etat» (p. 56). Le registre du commerce est institué en 1919 et la nationalité s'impose alors comme l'une des catégories d'identification des commerçants, justifiée par la nécessité d'une protection contre «l'envahissement étranger» (p. 60). Sous l'effet de la crise et de la montée du xénophobisme dans les années 1930, mais aussi des débuts de l'instauration d'une protection sociale des indépendants, les réglementations se durcissent à l'encontre des étrangers dans le monde du commerce ambulant, de l'artisanat, puis du petit commerce. De 1940 à 1944, ces restrictions aboutiront à l'exclusion stricte des entrepreneurs juifs.

Malgré leur difficulté d'utilisation, l'étude des registres du commerce a permis à Claire Zalc d'obtenir des données à l'échelle départementale (nombre d'inscriptions aux registres, d'ouvertures ou de fermetures par années, etc.) et sur les entrepreneurs euxmêmes (année de naissance, mariage, décès, etc.). La nationalité, enregistrée d'après des auto-déclarations, parfois étonnantes («brésilien arménien» ou «Israélite du Levant»), est une information de premier ordre pour l'historienne, qui peut ainsi reconstituer une partie de ce monde bigarré des commerçants étrangers. En mettant 
l'accent sur l'importance du statut d'indépendant, Claire Zalc montre la grande diversité des situations et des parcours, des commerces et des figures de commerçants, dont la liberté se paie au prix - parfois très lourd - de l'effort permanent, qu'ils soient «pionniers » ou «établis » dans le monde du commerce. A l'encontre des théories de l'entreprenariat ethnique, l'auteure montre comment, en France, les solidarités et les alliances économiques s'appuient bien plus sur des expériences communes, des parcours migratoires et professionnels, que sur une proximité d'origines. Les réseaux sociaux «construits dans l'immigration» et dans le monde de l'entreprenariat priment sur ceux qui se fondent sur une "'appartenance ethnique' finalement bien difficile à définir » (p. 161).

L'étude des quartiers d'immigration, où les boutiques jouent un rôle clé, est encore un apport majeur de cet ouvrage : Pletzl juif autour de la rue des Rosiers à Paris, Petites Italies de Nogent et de la Villette, Petite Espagne de La Plaine-Saint-Denis, Alfortville des Arméniens, Belleville métissé, etc. Faisant référence à l'Ecole sociologique de Chicago, Claire Zalc montre comment le fait de "tenir une boutique ou d'ouvrir un atelier revient à s'insérer d'une manière spécifique dans la ville» (p. 174). La localisation, matérialisée par une adresse, est alors primordiale, dans des logiques de regroupement ou de dispersion, où certains espaces sont définis comme des territoires d'accueil des «pionniers", tandis que d'autres, de seconde installation, sont réservés par des "établis ", les membres de ces deux groupes pouvant choisir de mettre plus ou moins en avant leur origine étrangère (par les enseignes, l'organisation des vitrines, etc.). Qu'ils soient marqués comme étrangers, à l'exemple du quartier italien de la Villette, ou perçus comme "parisiens", à l'exemple du Belleville de l'entre-deux-guerres (qui compte pourtant un nombre très important d'étrangers), ces quartiers, où les espaces de travail et les espaces domestiques sont imbriqués et souvent indissociables, permettent la constitution de réseaux sociaux et le maintien de solidarités communautaires.

$\mathrm{Au}$ total, le livre de Claire Zalc est vivant et passionnant. Il fait revivre au lecteur un monde aujourd'hui disparu tout en remettant en question des idées reçues encore très présentes aujourd'hui (sur les quartiers d'immigration ou les "spécialisations ethniques" par exemple). Une seule mise en garde cependant, pour ceux qui ne connaissent pas le travail de thèse dont est issu cet ouvrage, le titre accrocheur et le résumé de quatrième de couverture sont plus larges que le contenu, en grande partie centré sur les années 1920 et 1930 et sur Paris.

\author{
Marie Chabrol \\ Docteure en géographie \\ MIGRINTER - UMR 7301 \\ CNRS / Université de Poitiers \\ machabrol@gmail.com
}

